ORIGINAL

\title{
New evidence about thyroid cancer prevalence: prevalence of thyroid cancer in younger and middle-aged Japanese population
}

\author{
Shoichi Kikuchi ${ }^{1)}$, Takashi Takeshita ${ }^{1)}$, Hiroshi Shibata ${ }^{1)}$, Kazuo Hase ${ }^{2)}$ and Orlo H. Clark ${ }^{3)}$ \\ 1) Department of Surgery in Japan Self Defense Force Kumamoto Hospital, Kumamoto 862-0902, Japan \\ ${ }^{2)}$ Department of Surgery in National Defense Medical College, Tokorozawa 359-8513, Japan \\ ${ }^{3)}$ Department of Surgery in University of California, San Francisco 94122, USA
}

\begin{abstract}
We have made a cross-sectional investigation of men in the Japanese military for the presence of thyroid abnormalities and thyroid cancer to document the prevalence of thyroid disease in these persons. Six thousand, four hundred and twenty-two Japanese military men and women were screened for thyroid disease by history, physical examination and ultrasound examination. Among them, 6,182 were men 50 years of age, 47 were women 50 years of age, and 149 were men 40 years of age and 44 were women 40 years of age. Among the 50 years old men, thyroid nodules were found in 924 men (14.9\%): Nineteen individuals $(0.31 \%)$ had thyroid cancers ranging from $1 \mathrm{~mm}$ to $30 \mathrm{~mm}$ in diameter (12.5 mm in mean), pathological TNM staging revealed 7 cases of stage I, 2 cases of stage II and 9 cases of stage III. There was a significant increase in thyroid nodules in 50 years old men compared to that in 40 year old men, but there was no significant difference between men and women $(p>0.05)$. Our data document that the detection rate of thyroid cancer in 50 years old men was $0.31 \%$, and the rate of thyroid nodules increased with age in men, but the frequency of thyroid nodules were similar in men and women of the same age.
\end{abstract}

Key words: Prevalence of thyroid cancer, Younger and middle-aged Japanese men, Thyroid screening

SCREENING for thyroid disease in women during breast cancer screening is popular in Japan. Some studies concerning screening for thyroid disease have previously been reported in Japan $[1,3,4,16,17,23]$ and other countries $[2,5-15,18-21,24]$ The prevalence of thyroid nodule is reported to be from 1.2 [3] to $35.3 \%$ [9], and the prevalence of thyroid cancer is reported to be from 0.08 [12] to $3.9 \%$ [20]. Most of these studies primarily included women. The detection rate of thyroid nodule and thyroid cancer has been reported to be higher in women than that in men $[3,7$, $12,14]$. Screening for thyroid cancer in men, especially those nearing military retirement aged over 50 and 40 years old has not, to our knowledge, been previously done. We therefore investigated the frequency of thyroid nodules and thyroid cancers in military men at retirement and compared the data to a small number of

Submitted Nov. 16, 2012; Accepted Dec. 6, 2012 as EJ12-0420 Released online in J-STAGE as advance publication Jan. 17, 2013 Correspondence to: Shoichi Kikuchi, Japan Self Defense Force Kumamoto Hospital, 15-1 Higashihonmachi Higashiku, Kumamoto 862-0902, Japan. E-mail: shoichi_kikuchi@hotmail.com military women who were screened by physical examination and ultrasonography in Japan and in other countries to see whether thyroid nodule and cancer are more common in women than men.

\section{Materials and Methods}

Six thousand, four hundred and twenty-two Japanese military men and women were screened with questionnaire, physical examination and ultrasound examination for thyroid disease at the Japanese Self Defense Force Hospital (Central, Hanshin and Kumamoto) from 1990 to 2012. The prevalence of thyroid nodules (excluding pure thyroid cysts) and thyroid cancer was determined. All patients were asymptomatic. Patients with obvious thyroid symptoms were excluded from this database. Among studied patients, 6,182 were men 50 years of age, 47 were women 50 years of age, and 149 were men 40 years of age and 44 were women 40 years of age. No patient had a family history of thyroid cancer or had a past exposure to radiation. We defined "thyroid nodule" as the maximum diameter $\geq 3 \mathrm{~mm}$. We excluded the 
pure cysts, with about $6 \%$ of our study, from this study. The maximum diameter of thyroid nodule was also measured. Nodule $\geq 5 \mathrm{~mm}$ with suspicious characteristics of malignancy were considered for cytological examination by fine needle aspiration (FNA using TOSHIBA-SSA250A; the cycle of the probe is 7.5 Mega Hertz until 2002, and TOSHIBA-Aplio XG; 8 Mega Hertz from 2004). In case of inadequate specimen or difficulty for diagnosis, we usually repeated the FNA twice. Diffuse thyroid disease by ultrasonography, which was examined only at Japan Self Defense Force Kumamoto Hospital, was assessed by the definition in Thyroid Salivary Gland Atlas (Vector Core Inc.2004) [22]. Thyroid enlargement was defined as more than $20 \mathrm{~mm}$ in width or thickness, and thyroid atrophy as less than $10 \mathrm{~mm}$ in width and in thickness in its mid-section.

\section{Statistical analysis}

The significant differences between two groups were evaluated with the Chi Square test and Fisher's exact test. A two-sided $p$ value of $<0.05$ was considered statistically significant.

\section{Results}

\section{Thyroid screening}

50 years old men (Table 1)

Thyroid nodules including multinodular goiters and follicular neoplasms were found in 924 men (14.9\%). About $1 \%$ of 50 years old men had diffuse thyroid diseases.

40 years old men (Table 1)

Thyroid nodules were present in 12 men (8.1\%) and thyroid cancer was present in one man $(0.67 \%)$.

50 years old women (Table 1 )

Thyroid nodules were present in 5 women (10.6\%).

40 years old women (Table 1 )

Thyroid nodules were present in 5 women (11.3\%).

\section{Thyroid cancer of 50 years old men (Table $2 A, B$ )}

Sixty-three percent of thyroid cancers were papil- lary carcinomas, diagnosed preoperatively by fine needle aspiration. Twenty-six percent were occult cancers concomitant benign thyroid nodules detected postoperatively by pathological examination. Ten percent were minimally invasive follicular carcinomas detected postoperatively by pathological examination.

Nineteen individuals $(0.31 \%)$ were confirmed to have thyroid cancers ranging from $1 \mathrm{~mm}$ to $30 \mathrm{~mm}$ in maximum diameter $12.5 \mathrm{~mm}$ in mean. Clinical TNM staging revealed 8 cases of stage I, 4 cases of stage II and 6 cases of stage III. Pathological TNM staging revealed 7 cases of stage I, 2 cases of stage II and 9 cases of stage III. One patient diagnosed cytologically as papillary carcinoma denied the surgical treatment.

\section{Comparison the rate of thyroid nodule between age, and gender (Table $3 A, B, C$ )}

Fifty year old men had more thyroid nodules than 40 year old men. Men and women had a similar number of thyroid nodules.

\section{Discussion}

Our thyroid screening data of Japanese military 50 years old men revealed that $14.9 \%$ had thyroid nodules and $0.3 \%$ had histologically confirmed thyroid cancers (Table 1). Comparing our data of 50 years old men with those in 50 years old women, and 40 years old men and women, the detection rate of thyroid nodules in men had increased with age but that there was no significant difference between sexes. However, the detection rate of thyroid cancer in men had not increased with age. This will suggest that some small thyroid cancers will not always appear to be advanced cancers.

Prevalence of thyroid nodules and cancers reported in references was shown in Table 4. Our detection rate of thyroid cancer was similar [8, 12, 16, 17], or lower than that previously reported $[10,20]$. Chung [10] did thyroid screening, including for the patients with breast cancers, and Lin [20] reported screening for patients with thyroid nodules.

Table 1 Thyroid screening 1990 2012 (palpation+ultrasonography)

\begin{tabular}{lcccccc}
\hline Age & Gender & Case & Normal & Abnormal & Nodule & Cancer \\
\hline 50 years old & male & 6182 & 4983 & - & $924(14.9 \%)$ & $19(0.31 \%)$ \\
& female & 47 & 34 & $8(17.0 \%)$ & $5(10.6 \%)$ & 0 \\
\multirow{2}{*}{40 years old } & male & 149 & 87 & $34(22.8 \%)$ & $12(8.1 \%)$ & $1(0.67 \%)$ \\
& female & 44 & 25 & $16(36.3 \%)$ & $5(11.3 \%)$ & 0 \\
\hline
\end{tabular}

-, Unknown or not decided 
Table 2A Thyroid cancer 19 cases: 50 year old men

\begin{tabular}{lcccc}
\hline Thyroid cancer & Cases & Case/all patients & Case/thyroid cancer & remarks \\
\hline $\begin{array}{l}\text { Occult cancer } \\
\begin{array}{l}\text { Preoperatively diagnosed } \\
\text { papillary carcinoma }\end{array}\end{array}$ & 12 & $0.08 \%$ & $26.3 \%$ & $\begin{array}{c}\text { Concomitant benign } \\
\text { thyroid tumor }\end{array}$ \\
Follicular carcinoma & 2 & $0.2 \%$ & $63.2 \%$ & $10.5 \%$ \\
Total & 19 & $0.31 \%$ & $\begin{array}{c}2 \text { cases: } \\
\text { Minimally invasive }\end{array}$ \\
\hline
\end{tabular}

Table 2B Thyroid cancer 19 cases

\begin{tabular}{rcccccc}
\hline No & Surgery & Histology & pTNM & Stage & T(mm) & B \\
\hline 1 & Rt lobectomy+D1 & PTC, LN(-) & T1N0M0 & I & 15 & \\
2 & Rt lobectomy+D1 & PTC, LN(+) & T1N1M0 & III & 15 & \\
3 & Lt lobectomy+D1 & PTC(oc) & T1N0M0 & I & 1 & AN \\
4 & Rt lobectomy+D1 & PTC, LN(+) & T1N1M0 & III & 18 & \\
5 & Rt lobectomy+D1 & PTC, LN(+) & T2N1M0 & III & 20 & \\
6 & ST+D2 & PTC, LN(+) & T1N1M0 & III & 4 & \\
7 & Rt lobectomy+D1 & PTC(oc) & T1N0M0 & I & 1 & AN \\
8 & Rt lobectomy+D1 & PTC, LN(-) & T1N0M0 & I & 8 & \\
9 & Lt lobectomy+D1 & PTC, LN(+) & T2N1M0 & III & 20 & \\
10 & ST+D2 & PTC, LN(+) & T2N1M0 & III & 20 & \\
11 & ST+D2 & PTC(oc) & T1N0M0 & I & 1 & AN \\
12 & Rt lobectomy+D1 & FTC & T2N0M0 & II & 20 & \\
13 & Lt lobectomy+D1 & PTC, LN(+) & T1N1M0 & III & 8 & \\
14 & ST+D2 & PTC(oc) & T1N0M0 & I & 1 & AN \\
15 & Rt lobectomy+D1 & PTC(oc) & T1N0M0 & I & 1 & AN \\
16 & Rt lobectomy+D2 & PTC, LN(+) & T1N1M0 & III & 17 & \\
17 & Rt lobectomy+D1 & PTC, LN(+) & T1N1M0 & III & 18 & \\
18 & Rt lobectomy+D1 & FTC & T2N0M0 & II & 30 & \\
19 & - & PTC & - & - & $20 *$ & \\
\hline
\end{tabular}

PTC, papillary thyroid carcinoma; FTC, follicular thyroid carcinoma; ST, subtotal thyroidectomy; D, lymph node dissection; D1, central node dissection; D2, unilateral neck dissection; LN, lymph node metastasis; T, tumor size; B, concomitant benign thyroid nodule; AN, adenomatous nodule; oc, occult cancer, -, Unknown or not decided,; *, scale by ultrasonography

Table 3A Comparison between genders (50 years old)

\begin{tabular}{lccccc}
\hline 50 years old & Normal & Non-nodule & Nodule & Total & $p$ value \\
\hline male & 4,983 & 5,258 & $924(14.9 \%)$ & 6182 & \\
female & 34 & 42 & $5(10.6 \%)$ & 47 & 0.408 \\
\hline
\end{tabular}

Table 3B Comparison between genders (40 years old)

\begin{tabular}{lccccc}
\hline 40 years old & Normal & Non-nodule & Nodule & Total & $p$ value \\
\hline male & 87 & 137 & $12(8.1 \%)$ & 149 & \\
female & 25 & 39 & $5(11.3 \%)$ & 44 & 0.496 \\
\hline
\end{tabular}

Table 3C Comparison between age (40 vs. 50 years old in men)

\begin{tabular}{lcccccc}
\hline Age & Gender & Case & Normal & Non-nodule & Nodule & $p$ value \\
\hline 50 years old & male & 6,182 & 4,983 & 5,258 & $924(14.9 \%)$ & \\
40 years old & male & 149 & 87 & 137 & $12(8.1 \%)$ & 0.019 \\
\hline
\end{tabular}


Table 4 Prevalence of thyroid nodules and cancers reported in references

\begin{tabular}{lccccc}
\hline Reporters [ref] & Year & Total N (m:w) & Nodule (\%) (m:w) & Cancer (\%) (m:w) & Modality \\
\hline Maruchi [3] & 1967 & $30,359(14,002: 16,357)$ & $1.2(0.6: 1.7)$ & $0.13(0.08: 0.18)$ & $\mathrm{P}$ \\
Sampson [14] & 1974 & $157(99: 58)$ & - & $5.7(7.1: 3.5)$ & $\mathrm{A}$ \\
Harach [21] & 1985 & $101(-)$ & - & $35.6(43.3: 27.1)$ & $\mathrm{A}$ \\
Ishida [16] & 1986 & $152,651(-: 152,651)$ & - & $0.14(-: 0.14)$ & $\mathrm{U}$ \\
Omata [17] & 1986 & $198,824(13,538: 6,286)$ & - & $0.38(0.29: 0.59)$ & $\mathrm{U}$ \\
Struve CW [5] & 1993 & $212(-: 212)$ & $21.2(-: 21.2)$ & - & $\mathrm{U}$ \\
Hsiao YL [7] & 1995 & $1,020(618: 402)$ & $25.0(19.4: 33.6)$ & $0.7(0.6: 0.1)$ & $\mathrm{U}$ \\
Tomimori E [8] & 1995 & $547(167: 380)$ & $16.5(16.1: 16.5)$ & $0.18(-)$ & $\mathrm{U}$ \\
Wiest PW [12] & 1998 & $2,441(2,416: 25)$ & $10.2(10.1: 24.0)$ & $0.08(-)$ & $\mathrm{U}$ \\
Furlanetto TW [9] & 2000 & $207(-: 207)$ & $35.3(-: 35.3)$ & - & $\mathrm{U}$ \\
Chung WY [10] & 2001 & $1,401(-: 1,401)$ & $25.2(-: 25.2)$ & $2.6(-: 2.6)$ & $\mathrm{U}$ \\
Lin JD [20] & 2005 & $21,748(3,258: 18,490)$ & - & $3.9(5.7: 3.6)$ & $\mathrm{U}$ \\
Hurtado-Lopez LM [25] & 2011 & $2,401(423: 1,978)$ & $19.6(-)$ & $0.08(-)$ & $\mathrm{U}$ \\
\hline P, palpation; U, ultrasonography with palpation; A, autopsy; ref, reference number; m, men; w, women; -, Unknown \\
or not decided
\end{tabular}

To our knowledge thyroid screening of 40 and 50 years old military men has not been previously reported, whereas it has been reported in women. One of the reasons is that thyroid disease is thought to be more common in women. Other screening investigations predominantly including women has also been reported in Japan $[1,3,4,16,17]$ and other countries $[2,5-15$, 18-21,24]. According to the literature, the detection rate of thyroid nodules and thyroid cancers is higher in women than that in men. Most of these reports state that thyroid cancer detection rate is higher in women than that in men [24], especially in 30 and 40 years old patients $[1-4,6,8,11,13,15-18]$.

Dal Masio et al. [24] reported that the highest frequency of papillary thyroid carcinoma was observed at 45 49 years old women and at 65 69 years old men. Concerning the gender differences, Kugimoto and Maruchi $[1,3]$ reported on 30,359 subjects $(86.4 \%$ of the total inhabitants of the area studied - Nagano, Japan) from 1965 through 1967, and found thyroid cancers in $0.08 \%$ in men and $0.18 \%$ in women. Ishida et al. [16] examined 152,651 women and found $0.14 \%$ with small, but detectable, thyroid cancers by mass screening. Omata et al. [17] observed an incidence of $0.29 \%$ in men and $0.59 \%$ in women, totally $0.38 \%$ in 19,821 subjects, using ultrasound that is capable of detecting tumors as small as $4 \mathrm{~mm}$. On the contrary, Hsiao reported that the rate of thyroid cancer in men is $0.6 \%$ which is higher than that in women $(0.1 \%)$ [7]. Lin reported that the rate of thyroid cancer in men is $5.7 \%$ which is higher than that in women (3.6\%) [20]. Furthermore, micro- scopic thyroid cancer is extremely common at postmortem examination $[14,21]$. The prevalence rate of $7.1 \%$ in men and $3.5 \%$ in women was reported by Sampson in157 consecutive autopsies [14]. The highest prevalence rate of $35.6 \%$ with $43.3 \%$ in men and $27.1 \%$ in women was reported by Harach in 101 consecutive autopsies in patients from Finland [21].

Among, 19 thyroid cancers $(0.31 \%)$ of 50 years old men, $63.2 \%$ were diagnosed preoperatively by fine needle aspiration biopsy (FNA) using ultrasonograpy, $26.3 \%$ were occult cancers concomitant benign thyroid nodules that were diagnosed postoperatively by pathological examination, and $10.5 \%$ were minimally invasive follicular carcinomas that were also diagnosed postoperatively by pathological examination. We might have missed more thyroid cancers, because the indication of FNA for thyroid nodules were more than $5 \mathrm{~mm}$, and most patients with benign thyroid nodules would not have surgery. The accurate thyroid cancer prevalence is thought to be more than $0.3 \%$.

Another interesting fact that we reported is that pathological TNM staging revealed 7 cases of stage I, 2 cases of stage II and 9 cases of stage III. About $50 \%$ of thyroid cancer screened among asymptomatic 50 years old men had already lymph nodes metastasis. Considering the prognosis of thyroid cancer in elderly men, the thyroid screening using ultrasonography is a more effective and efficient way to identify thyroid cancer at an early stage in middle-aged Japanese population.

However, screening for thyroid cancer has not been recommended in USA. One reason is that most thy- 
roid cancers are clinically of little consequence. A second reason is that many thyroid cancers identified by screening will not affect the patient's prognosis. In autopsy studies, the prevalence of occult cancer in adults ranges from 2 to $35.6 \%[13,14,21]$, in contrast, the annual incidence of clinical thyroid cancer is only 4/100,000 [4, 15]. Microscopic thyroid cancers are found more frequently at autopsy, or when thyroid gland is screened for others pathology, whereas clinically evident thyroid cancer occurs in only about one out of 100 ultrasonographically detectable thyroid nodules. However, a cohort study of mass screening found a significantly higher 7-year cumulative survival rate in patients whose thyroid cancers were detected by screening (98\%) when compared with those presenting with symptoms $(90 \%)$ [16]. This data suggests that patients with small thyroid cancers detected by screening have a favorable course. But to our knowledge, it has not been demonstrated that the detection of patients with thyroid cancer by screening have a better outcome than those having larger tumors and/or clinical symptoms. The American Cancer Society recommends screening for thyroid cancer by palpation every 3 years in persons aged 21-40 years and annually in those more than 40 years old [19].

We suggest that thyroid screening using ultrasonography is a more effective and efficient way to identify thyroid cancer at an early stage in middle-aged Japanese population.

The limitations of this study are that this is the retrospective study and that the number of 50 years old women, 40 years old men and women was small.

\section{Conclusion}

Our data demonstrate that the detection rate of thyroid cancer in retiring Japanese military men (50 years old men) was $0.31 \%$, which is similar to the known rate reported in the literature, and the number of thyroid nodules increased with age in men, but the rate of thyroid nodules is the same between the genders with the same age. Thyroid screening using ultrasonography is currently the most sensitive method for identifying thyroid nodules and cancer at an early stage in younger and middle-aged Japanese men.

\section{References}

1. Kugimoto M, Maruchi N (1967) A statistical study of death for malignant neoplasm of thyroid gland. Med $J$ Shinshu Univ 12: 65-77 (In Japanese).

2. Flynn MB, Tarter J, Lyons K, Ragsdale T (1991) Frequency and experience with carcinoma of the thyroid at a private, a Veterans Administration, and a university hospital. J Surg Oncol 48: 164-170.

3. Maruchi N (1967) Epidemiological studies on thyroid carcinoma report 1.Epidemiological and clinical approach of thyroid carcinoma on field surveys in Nagano prefecture. Shinshu Med J 16: 255-265 (In Japanese).

4. Koike A, Naruse T (1991) Incidence of Thyroid Cancer in Japan. Semin Surg Oncol 7: 107-111.

5. Struve CW, Haupt S, Ohlen S (1993) Influence of frequency of previous pregnancies on the prevalence of thyroid nodules in women without clinical evidence of thyroid disease. Thyroid 3: 7-9.

6. Ezzat S, Sarti DA, Cain DR, Braunstein GD (1994) Thyroid incidentalomas. Prevalence by palpation and ultrasonography. Arch Intern Med 154: 1838-1840.

7. Hsiao YL, Chang TC (1995) Prevalence of goiter in Taiwanese adults: a preliminary study. J Formos Med Assoc 94: 197-199.

8. Tomimori E, Pedrinola F, Cavaliere H, Knobel M,
Medeiros-Neto G (1995) Prevalence of incidental thyroid disease in a relatively low iodine intake area. Thyroid 5: 273-276.

9. Furlanetto TW, Peccin S, de O Scheider MA, dos S Zimmer A, dos Reis PS, et al. (2000) Prevalence of thyroid nodules in 40 years-old or old women. Rev Assoc Med Bras 46: 331-334.

10. Chung WY, Chang HS, Kim EK, Park CS (2001) Ultrasonographic mass screening for thyroid carcinoma: a study in women scheduled to undergo a breast examination. Surg Today 31: 763-767.

11. Tan GH, Gharib H (1997) Thyroid incidentalomas: management approaches to nonpalpable nodules discovered incidentally on thyroid imaging. Ann Intern Med 126: 226-231.

12. Wiest PW, Hartshorne MF, Inskip PD, Crooks LA, Vela BS, et al. (1998)Thyroid palpation versus high-resolution thyroid ultrasonography in the detection of nodules. J Ultrasound Med 17: 487-496.

13. Mortensen JD, Woolner LB, Bennett WA (1955) Gross and microscopic findings in clinically normal thyroid glands. J Clin E docrinol Metab 15: 1270-1280.

14. Sampson RJ, Woolner LB, Bahn RC, Kurland LT (1974) Occult thyroid carcinoma in Olmsted County, Minnesota: prevalence at autopsy compared with that 
in Hiroshima and Nagasaki, Japan. Cancer 34: 20722076.

15. Clark OH, Duh QY (1991) Thyroid cancer. Med Clin North Am 75: 211-234.

16. Ishida $T$, Izuo $M$, Ogawa $T$, Kurebayashi J, Satoh K (1988) Evaluation of mass screening for thyroid cancer. Jpn J Clin Oncol 18: 289-295.

17. Omata K, Iguchi K, Iida R, Ozawa T, Kusano T, Naoe S, Tanaka N (1986) Clinico-pathological study of thyroid carcinomas detected by mass screening. Gan No Rinsho 32: 740-748 (In Japanese).

18. Shimaoka K, Bakri K, Sciascia M, Razack M, Rao U, et al. (1982) Thyroid screening program: follow-up evaluation. N Y State J Med 82: 1184-1187.

19. Mettlin C, Jones G, Averette H, Gusberg SB, Murphy GP (1993) Defining and updating the American Cancer Society guidelines for the cancer-related checkup: prostate and endometrial cancers. CA Cancer J Clin 43: 42-46.

20. Lin JD, Chao TC, Huang BY, Chen ST, Chang HY, et al.
(2005) Thyroid cancer in the thyroid nodules evaluated by ultrasonography and fine-needle aspiration cytology. Thyroid 15: 708-717.

21. Harach HR, Franssila KO, Wasenius VM (1985) Occult papillary carcinoma of the thyroid. A "normal" finding in Finland. A systemic autopsy study. Cancer 56: 531536.

22. (2004) Thyroid Salivary gland Atlas. Vector Core Inc., Japan.

23. Kikuchi S, Hase K (2011) Prevalence of thyroid cancer in middle-aged Japanese population. National Defense Medical J 36:15-21.

24. Dal Maso L, Lise M, Serraino D (2011) Incidence of thyroid cancer in Italy. 1991-2005; time trends and ageperiod-cohort effects. Ann Oncol 22: 957-963.

25. Hurtado-Lopez LM, Basurto-Kuba E, Montes de ODER. Pulido - Cejudo A, Vazquez-Ortega R, AthieGutierrez C (2011) Prevalence of thyroid nodules in the Valley of Mexico. Cirugia y cirujanos 79: 114-117. 